\title{
Exploring the role of humor in the management of existential anxiety
}

\begin{abstract}
The current study addressed a topic that has both theoretical and applied importance, by examining the potential existential anxiety-buffering function of humor. Participants $(\mathrm{N}=556$; $55 \%$ female; $\mathrm{M}$ age $=37$ years) completed a measure of trait coping humor before being randomly assigned to a mortality salience condition and a humor induction condition and then completing a measure of death-thought accessibility. ANOVA revealed main effects of trait coping humor, mortality salience and humor induction on death-thought accessibility in the expected directions. Coping humor interacted with mortality salience $(\mathrm{F}(1,439)=14.47$, $\mathrm{p}<.01)$ showing that low coping humor participants were more affected by the mortality salience manipulation. Coping humor also interacted with humor induction $(F(1,439)=8.94$, $\mathrm{p}<.01)$ showing that low coping humor participants were more affected by the humor induction. Findings suggests that whilst trait coping humor appears to buffer the effects of mortality salience, those low in trait coping humor may benefit the most from interventions aimed at reducing existential anxiety via humor. The apparent beneficial effect of humor induction for individuals low in coping humor holds a promise of advancing our understanding of existential threat and, ultimately, providing a basis for interventions to improve mental health.
\end{abstract}

Keywords: coping humor, terror management theory, existential anxiety 


\section{Introduction}

Research evidence suggests that humor can function as an effective means of coping with pressured or traumatic experiences in contexts such as mental and physical health (Demjén 2016, Merz et al. 2009, Romundstad et al. 2016, Rudnick et al., 2014) occupational stress (Sliter et al. 2014, Tremayne 2014), workplace bullying (Wilkins 2014), stereotype-threat (Ford et al. 2004), care-giving (Jarvis et al. 2006), pregnancy (Shirley 2015) and aging (Berk 2015, Marziali et al. 2008). In the field of positive psychology, researchers have identified humor as one of 24 character strengths that enable human flourishing. Following a review of literature from world religions, psychiatry, psychology, philosophy and popular culture, the Values in Action Classification of Strengths and Virtues (VIA-CSV; Peterson and Seligman 2004) described six overarching virtues (wisdom, courage, humanity, justice, temperance and transcendence) encompassing 24 different character strengths, which are valued across cultures and contribute to individual wellbeing. According to Peterson and Seligman (2004, p530), the character strength of humor (which falls under the virtue of transcendence) is exemplified by someone "who is skilled at laughing and gentle teasing, at bringing smiles to the faces of others, at seeing the lighter side, and at making (not necessarily telling) jokes".

Much of the theoretic and empirical psychology literature on humor takes either a cognitive or a motivational approach (Hackney 2011). Cognitive accounts focus on the nature of humorous material which often involves conceptual or linguistic incongruity, whereby expectations are established and then violated (Bartolo et al. 2006, Brône et al. 2006, Rozin et al. 2006). Motivational accounts focus on the psychological purpose of humor and include humor's function as an adaptive defensive mechanism for dealing with mental anxiety (Valliant 2000).

A recurring theme in the motivational literature is humor's function as a buffer against existential anxiety, that is, our awareness and fear of our own death. Existential perspectives on humor propose that humor's primarily function is to address mortality concerns; whilst we cannot control death's inevitability, we can choose how we react to humorous material, which offers us a means of reasserting control (Elgee 2003). Gallows humor, a term used by Freud to describe condemned prisoners making light-hearted jokes on their way to the gallows, is a form of dark humor that makes light of existential concerns, often used in times of crisis as a means to reassert control in uncontrollable circumstances (Maxwell 2003, Frankl 1946). Other motivational accounts see humor as a means of facilitating social interactions (Fine and DeSoucey 2005), for example by establishing and enforcing shared rules, maintaining a sense of group membership or maintaining boundaries between in-groups and out-groups. Evolutionary theories of humor and related positive emotional states, such as laughter and playfulness, emphasize the social function of jokes and laughter for enhancing group cohesion, either by strengthening bonds with members of one's in-group, or by excluding or derogating members of one's out-group (Alexander 1986, Frederickson 2001, Keltner et al. 2001, Owren and Bachorowski 2003, Shitoa et al. 2004).

Motivational accounts of humor are consistent with the perspective of Terror Management Theory (Greenberg et al. 1986), heavily influenced by Ernest Becker who argues that human society has established a wealth of cultural views, beliefs, values and behaviors that provide us with a means to transcend death in some way. By investing in a cultural world view, an individual can achieve a sense of immortality, either literally, in the case of an afterlife provided by religion, or symbolically. Greenberg et al. (1986) developed this theory into a testable psychological model in which existential terror is managed by an anxiety buffer. The anxiety buffer has two components: the first is the belief in a cultural world view; and the second is self-esteem, achieved when one feels one is living up to the standards set out by one's cultural world view. Hart et al. (2005) extended the theory with 
their model of a tripartite terror-management system, comprising dynamically interrelated attachment, worldview and self-esteem processes. This model integrates attachment theory and terror management theory, proposing that much of human behavior is aimed at maintaining a sense of psychological security and reducing conscious and unconscious anxiety about personal vulnerability (and ultimately, death). Close relationships, cultural belief systems and self-esteem all offer a means of enhancing psychological security and decreasing anxiety. Researchers in this field have devised methods to experimentally manipulate mortality salience (that is, awareness by an individual that her death is inevitable), in order to gauge the effect this has on a variety of different social behaviors. The thoughts, feelings or behaviors that result from increased mortality salience are collectively understood and referred to in this literature as 'worldview defense' or 'death anxiety-induced defensiveness. Studies have shown that 1) threats to participants' sense of attachment activate the same worldview defense and self-esteem enhancement behaviors that are activated by mortality salience, and 2) when participants' worldview or sense of self-esteem is threatened, they respond with attachment-related proximity-seeking or avoidance behavior (Hart et al. 2005). Thus, threats to one component of the tripartite security system (relating to attachment, worldviews or self-esteem) appear to result in compensatory defensive activation of the other components.

Humor could potentially play a role in all three elements of the tripartite security system. Humor can allow people to maintain a positive outlook in the face of adversity (Merz et al. 2009, Demjen 2016), it can facilitate the initiation and maintenance of satisfying interpersonal relationships (Peterson \& Seligman 2004), and it can be used to ostracize others or denigrate out-group members in order to bolster one's own cultural worldview (Elgee 2003).

Other elements of humor which may help to buffer existential anxiety include selfdeprecation, discordance and emotional distancing, as outlined below. Self-deprecation is often an ingredient of humor, and this may serve a terror-management function via a sense of humility, or a knowledge of one's limitations and imperfections. Humility is identified as a character strength (Peterson \& Seligman, 2004) which along with humor and spirituality is an exemplar of the aforementioned virtue of transcendence. Research has found that a quiet ego (measured by self-reported humility and low psychological entitlement) is associated with lower death anxiety and less death anxiety-induced defensiveness; experimentally inducted humility also protects against death anxiety and its negative effect on self-regulation (Kesebir 2014).

Discordance, incongruity or the violation of expectations is another common ingredient in humor (Rozin et al. 2006) that may be relevant to its potential use as an existential anxiety buffer. Humor is often about the apparent disconnect between reality and one's personally held cultural worldview. Research has shown that tolerance for ambiguity moderates the effect of mortality salience on death anxiety and death anxiety-induced defensive behaviors in certain contexts (Landau et al. 2006, Vess et al. 2009). Participants who are particularly averse to ambiguity, who score high on trait measures of personal need for structure (PNS) become even more intolerant of ambiguity when death becomes salient, indicating that the need for structure itself may be related to mortality concerns.

Finally, emotional distancing is sometimes required to appreciate dark or "gallows" humor. People higher in appreciation of perspective-taking humor, which involves being able to distance oneself from the emotional consequences of aversive experiences, appear to be less disturbed by death-related thoughts (Lefcourt 1995). Under conditions of mortality salience, jokes are found funniest when they are more closely related to themes of death and out-group derogation as opposed to a more neutral theme (Hackney 2011). All of this 
suggests that a sense of humor in general or the appreciation of certain types of jokes can serve as an existential anxiety buffer.

Previous correlational research has found that individuals with high levels of trait death anxiety report a lower appreciation for humor in general (Mager and Cabe 1990). The current study aimed to further explore the potential existential anxiety-buffering function of humor, by examining the effects of trait coping humor and experimentally manipulated humor on death anxiety. Death anxiety was operationalized in this study by measuring deaththought accessibility, that is, the availability in conscious awareness of death-related thoughts. It was hypothesized that trait coping humor would be negatively associated with death-though accessibility, and experimentally-induced humor would reduce death-thought accessibility. It was also hypothesized that trait coping humor and experimentally manipulated humor would both moderate the effect of mortality salience on death-thought accessibility.

\section{Method}

\subsection{Design}

A 2 (high trait coping humor vs. low trait coping humor) x 2 (mortality salience vs. pain salience) x 2 (funny film clip vs. neutral film clip) independent experimental design was employed.

\subsection{Participants}

Participants $(\mathrm{N}=556 ; 56 \%$ female; $M$ age $=37$ years, $S D=14.13)$ were recruited via a social networking site to take part in an online experiment. Most participants (55\%) were in full-or part-time employment ( $22 \%$ were unemployed, $16 \%$ were students, $7 \%$ were retired).

\subsection{Measures}

\subsubsection{Coping humor}

This was measured with the seven-item self-report coping humor scale (Lefcourt 2001) which was designed to measure the degree to which people make use of humor in coping with stress in their lives. Example items include "I can usually find something to laugh or joke about even in trying situations" and "I often lose my sense of humor when I am having problems" (reverse-scored). Statements are scored on a Likert scale ranging from 1(strongly disagree) to 4 (strongly agree). Cronbach's alpha coefficient for the current sample was .80 with one item deleted. This item ("I often lose my sense of humor when I am having problems") was removed in order to obtain an acceptable Cronbach's alpha coefficient; the relatively low correlation between participants' scores on this item and their scores on the other items in the scale may reflect varying interpretations of what constitutes 'losing one's sense of humor', or 'having problems', in our sample.

\subsubsection{Mortality salience manipulation}


Consistent with previous research (e.g. Landau et al. 2006), mortality salience was manipulated by asking participants two questions about death: "Please briefly describe the emotions that the thought of your own death arouses in you," and "Jot down, as specifically as you can, what you think will happen to you once you are physically dead." Control participants responded to parallel questions regarding the experience of dental pain.

\subsubsection{Humor manipulation}

Following research which shows mortality salience effects are best observed after a delay (Arndt et al. 1997), participants were presented with a ten minute video-clip which doubledup as a ten-minute delay task. In the humor induction condition, participants watched a humorous video (a 10 minute clip of Mr. Bean figure-skating). Mr. Bean is a physical comedy character devised by Rowan Atkinson which has enjoyed international mainstream success. In the control group, participants watched a neutral video with matched content (a 10 minute clip of the 1989 World Figure Skating championships).

\subsubsection{Death thought-accessibility}

This was operationalized by measuring the availability in conscious awareness of deathrelated thoughts. Participants were asked to solve a list of 22 anagrams, six of which had one death-related solution and one non-death-related solution (Arndt et al. 1997). For example, the word- fragment $\mathrm{COFF}_{-}$_ could be completed as COFFIN (death related) or COFFEE (not death-related). Participants' death-though accessibility was measured as the number of death-related anagram solutions they found.

\subsection{Procedure}

Participants were invited to take part in an online study on personality and coping via advertisements on a social networking site. After obtaining informed consent, measures and manipulations were presented to participants using online survey software. All participants completed the self-report measure of trait coping humor before being randomly assigned to one of two mortality salience conditions (mortality salience or dental pain). Participants were then randomly assigned again to one of two humor conditions in which they watched a tenminute video clip (funny or neutral). Finally, all participants completed the death thoughtaccessibility measure before being fully debriefed.

It was particularly important to consider the ethics of using mortality salience in an online research context involving remote data collection. The potential for experiencing distress as a result of taking part in the study was clearly sign-posted on the consent form without making mortality salient, and participants were advised that they could skip over any questions they did not wish to answer. Participants were also asked to confirm that they were over 18 years of age and that they had not recently experienced a stressful life event. This study received ethical approval from the relevant University Research Ethics Committee.

\section{Results}


A 2 (high/low coping humor) x 2 (mortality salience/control) x 2 (humor induction/control) ANOVA was carried out to test the following five hypotheses:

\subsection{H1) Trait coping humor will be negatively associated with death-thought accessibility}

It was predicted that the more regularly a person uses coping humor, the less available deaththoughts will be in their conscious awareness. In other words, when solving the anagrams with two possible solutions (one death-related and one neutral), participants who more regularly use coping humor will find less death-related solutions, whereas those who rarely use coping humor will find more death-related solutions.

\subsection{H2) Humor induction will reduce death-thought accessibility}

It was expected that experiencing the humor induction (that is, viewing the humorous video) would cause death-thoughts to become less available in conscious awareness. In other words, participants who viewed the humorous video (experimental condition) would find less deathrelated solutions to the anagrams, compared to those who viewed the matched, neutral video (control condition).

\subsection{H3) Trait coping humor will buffer the effect of mortality salience on death-thought accessibility}

Death reminders were expected to cause an increase in the accessibility of death-thoughts in conscious awareness; however, we predicted that these effects would be moderated by trait coping humor. In other words, the effect of mortality salience on the amount of death-related anagram solutions offered by a participant would depend on how regularly that participant uses coping humor.

\subsection{H4) Humor induction will buffer the effects of mortality salience on death-thought accessibility}

Death reminders were expected to cause an increase in the accessibility of death-thoughts in conscious awareness; however, we also predicted that these effects would be moderated by humor induction. In other words, the effect of mortality salience on the amount of deathrelated anagram solutions offered by a participant would depend on whether that participant viewed the humorous video (experimental condition), or the matched, neutral video (control condition).

\subsection{H5) Humor induction will interact with trait coping humor to predict death-thought accessibility}

Humor induction was expected to cause a decrease in the accessibility of death-thoughts in conscious awareness (hypothesis two); however, we also predicted that this effect would be moderated by trait coping humor. In other words, the effect of watching the humorous video 
(versus the matched neutral video) on the number of death-related anagram solutions offered by a participant would depend on how regularly that participant uses coping humor.

Participants' scores on trait coping humor ranged from 1 (strongly disagree) to 4 (strongly agree), $M=2.84, S D=.68$ ). Coping humor scores were split at the median (3.00) to create a dichotomous trait coping humor score (high or low) for each participant. Descriptive statistics for death-thought accessibility across categories and conditions are shown in table 1 .

Table 1. Descriptive statistics for death-thought accessibility across conditions

\begin{tabular}{|c|c|c|c|c|c|}
\hline Mortality salience & Coping Humor & Humor Induction & Mean & Std. Deviation & $\mathrm{N}$ \\
\hline \multirow[t]{4}{*}{ Death } & Low & Neutral Video & .70 & .33 & 52 \\
\hline & & Funny Video & .46 & .19 & 62 \\
\hline & High & Neutral Video & .38 & .23 & 57 \\
\hline & & Funny Video & .29 & .18 & 64 \\
\hline \multirow[t]{4}{*}{ Dental Pain } & Low & Neutral Video & .43 & .23 & 59 \\
\hline & & Funny Video & .27 & .15 & 46 \\
\hline & High & Neutral Video & .29 & .18 & 51 \\
\hline & & Funny Video & .23 & .16 & 56 \\
\hline
\end{tabular}

There was a significant main effect of condition on death-thought accessibility, suggesting that the mortality salience manipulation worked $(\mathrm{F}(1,439)=58.43, \mathrm{p}<.01)$. In support of hypothesis one, there was a significant main effect of coping humor scores on death-thought accessibility $(F(1,439)=68.70, p<0.01)$, which was significantly lower for participants high in coping humor $(M=0.30, S D=0.19)$ compared to those low in coping humor $(M=0.47, S D=0.28)$. In support of hypothesis two, there was a significant main effect of humor induction on death-thought accessibility $(\mathrm{F}(1,439)=48.40, \mathrm{p}<0.01)$, which was significantly lower for participants who had watched the humorous video $(M=0.31, S . D$ $=0.20)$ compared to the neutral video $(M=0.45, S D=0.28)$.

In support of hypothesis three, trait coping humor interacted with mortality salience to predict death-thought accessibility $\left(F(1,439)=14.47, p^{<.01}\right)$, showing that low coping humor participants were more affected by the mortality salience manipulation than high coping humor participants were (see figure 1). Follow-up t-tests showed that the effect of mortality 
salience on death-thought accessibility was significant both for those low in coping humor $(t(206.40)=-6.08, \mathrm{p}<0.01)$ and those high in coping humor $(t(226)=-3.01, \mathrm{p}<0.01)$.

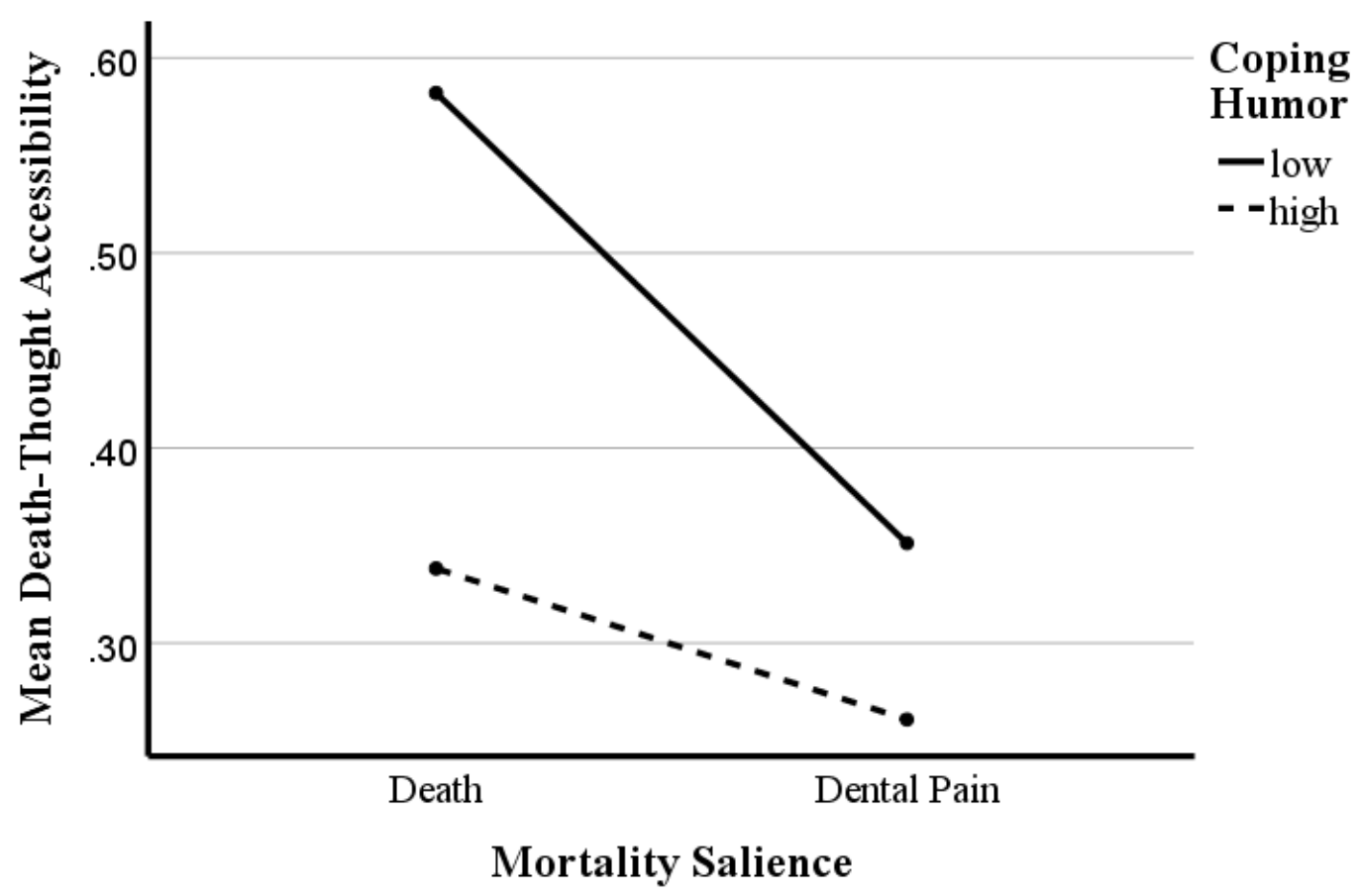

Figure 1. Interaction effect of coping humor and mortality salience on death-thought accessibility score.

There was no significant interaction of humor induction and mortality salience condition on death-thought accessibility $(\mathrm{F}(1,438)=1.87, \mathrm{p}>.05)$, leading to the rejection of hypothesis four. In support of hypothesis five, trait coping humor interacted with humor induction to predict death-thought accessibility $(F(1,439)=8.94, p=0.01)$ showing that low coping humor participants were more affected by the humor induction than high coping humor participants were (see figure 2). Follow-up t-tests showed that the effect of humor induction on death-thought accessibility was significant both for those low in coping humor $(\mathrm{t}(186.98)=5.06, \mathrm{p}<0.001)$ and those high in coping humor $(\mathrm{t}(226)=3.18, \mathrm{p}<0.01)$. 


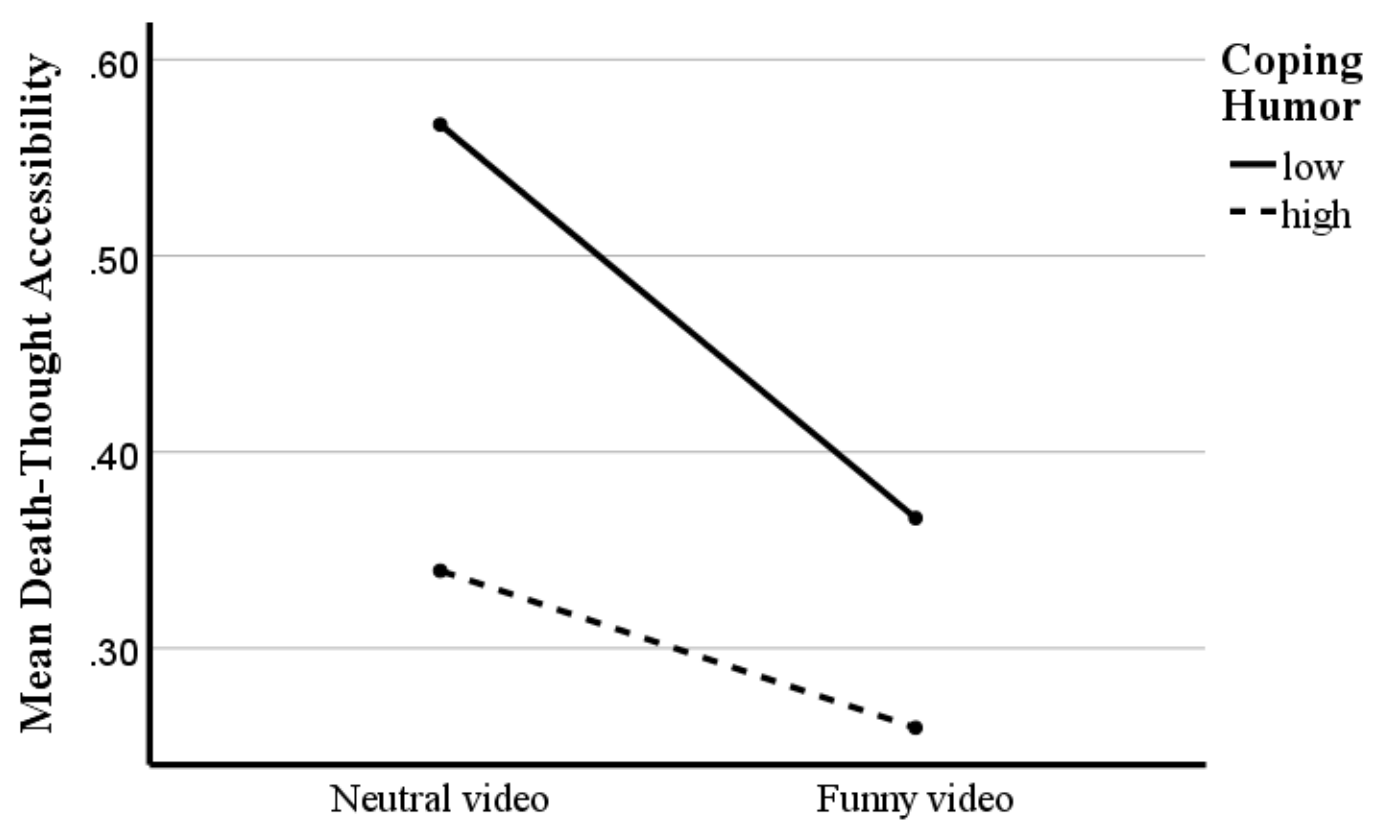

Humor Induction

Figure 2. Interaction effect of coping humor and humor induction on death-thought accessibility scores.

\section{Discussion}

Four of the five hypotheses were supported by the current findings. Death-thought accessibility across conditions was lower for those high in trait coping humor (hypothesis one), suggesting that the tendency to make use of humor to cope with stress acts as an existential anxiety buffer. In other words, a person who regularly uses coping humor has less access to death-related thoughts in her conscious awareness compared to someone else who rarely uses coping humor. This finding implies that people who regularly use coping humor are better at managing every-day existential anxiety than those who rarely use coping humor; these people have less access to death-related thoughts in their conscious awareness regardless of whether or not mortality has been made salient. This finding is consistent with previous research that found a negative correlation between trait death anxiety and appreciation for different types of humor (Mager and Cabe 1990).

To further qualify this finding, trait coping humor interacted with mortality salience to predict death-thought accessibility (hypothesis three), showing that participants who were high in trait coping humor were less severely affected by the mortality salience manipulation. This suggests that coping humor can buffer classic mortality salience effects but cannot eliminate them completely. In other words, a person who regularly uses coping humor, upon being reminded of her mortality, is more able to suppress her resulting death-related thoughts below her conscious awareness compared to someone who rarely uses coping humor, yet she is not able to suppress these death-related thoughts completely. This finding implies that people who regularly use coping humor are better at managing experimentally manipulated existential anxiety than those who rarely use coping humor. 
Participants who viewed a humorous video clip in the current study reported lower death-thought accessibility across conditions compared to those who viewed a neutral video clip (hypothesis two), which suggests that experimentally induced humor can also act as an existential anxiety buffer. In other words, regardless of mortality salience condition, participants who viewed the clip of Mr. Bean figure-skating offered less death-related anagram solutions than did participants who viewed the clip of the 1989 World FigureSkating Championships. To further qualify this finding, trait coping humor interacted with humor induction to predict death-thought accessibility (hypothesis five), showing that the aforementioned effect of the humor induction was more pronounced for those low in coping humor. In other words, participants who were low in coping humor benefitted the most from the mortality salience-buffering effect of humor induction. This suggests that whilst humor induction can buffer existential anxiety for those high and low in coping humor, it is more effective for those who have low coping humor. A possible explanation for this relates back to the idea outlined above that those who rarely use coping humor are less practiced terrormanagers; they do not routinely use humor to buffer existential anxiety, they have higher death-thought accessibility scores both at baseline (hypothesis one) and when mortality is made salient (hypothesis three), and they have more to gain from a humor induction.

The hypothesis four, that humor induction will buffer the effects of mortality salience on death-thought accessibility, was not supported. This means that participants were just as severely affected by the mortality salience manipulation whether they viewed the humorous video of Mr. Bean Figure Skating or the neutral video of the World Figure Skating Championships. In other words, whilst the humor induction successfully reduced baseline death-thought accessibility, particularly for those low in coping humor, it was not able to do the same following our mortality salience manipulation. Participants, after being asked to write about what they think will happen when they physically die and how this makes them feel, experienced higher death-thought accessibility whether or not they viewed the humor induction video clip. Our findings suggest that whilst humor induction can reduce baseline existential anxiety, it may not be as effective in situations where mortality is extremely salient.

The current study is exploratory in nature and raises several interesting questions for further research. Whilst findings demonstrate that both trait coping humor and experimentally induced humor can buffer existential anxiety, it is not known which aspects of the humor induction (that is, which types of humor) caused the buffering effect. The main limitation of the current study was that unedited, pre-existing video-clips were chosen for the humor manipulation. The humor induction was a 10 minute video-clip of 'Mr. Bean' figure-skating. This was chosen because of the character's international and mainstream popular appeal and because the comedy is physical or slapstick in nature, rather than involving dialogue. This also presented the opportunity to use a 10-minute video-clip of the 1986 World FigureSkating Championships as a matched control group. However, a limitation of using preexisting, unedited video-clips is that not all content could be matched exactly. A further limitation is that video content was not independently rated for humor type prior to the study. The primary source of humor in the series 'Mr. Bean', which was heavily influenced by physical performers and silent film actors, is slapstick comedy, arising through Mr. Bean's interactions with other people and his unusual solutions to situations (British Comedy Guide 2017). Martin et al. (2003) differentiated four dimensions in individuals' use of humor, which they called self-enhancing (used to enhance the self), affiliative (used to enhance social relationships), aggressive (used to enhance the self at the expense of others) and selfdefeating (used to enhance relationships at the expense of the self). Without the independent rating of video content and further manipulation checks, it is not possible to know which of these humor dimensions, if any, were induced by the clip. One can speculate, however, that 
self-enhancing and aggressive humor may have been induced since Mr. Bean's character is simultaneously a non-conformist out-group member and sometime object of derision. A further limitation of the study is that due to a clerical error, manipulation check data for the humor induction were not recorded, so it is not possible to say how funny participants found the Mr. Bean clip, compared to the neutral clip.

Nonetheless, these findings have both theoretical and applied importance. Examining the potential mortality-salience-buffering function of humor holds a promise of advancing our understanding of existential threat, which, ultimately, may provide a basis for interventions to improve mental health. Furthermore, these findings also provide empirical support for existing therapeutic interventions involving humor. Some hospitals in USA have formal humor programs in which staff provide laughter rooms, therapeutic clowns and comedy carts filled with humorous books, videos and other items for patients (Bennet 2003). Firstly, the current findings suggest that coping humor can buffer existential anxiety at baseline and when mortality is made salient, leading to the possibility of encouraging or teaching coping humor as a useful strategy. Secondly, our findings suggest that it may be possible to buffer existential anxiety with experimentally induced humor, with the caveat that when mortality is extremely salient, long-term strategies aimed at fostering trait coping humor may be more fruitful than a single humor induction. In hospital settings, where physical vulnerability and ultimately death are highly salient, the management of existential anxiety could potentially deliver both psychological and physical benefits to patients. Furthermore, whilst all patients may benefit from humor interventions, those low in coping humor may benefit the most. Counter-intuitively, it may be that the patients who do not routinely seek out humor as their preferred coping style would have the most to gain from a hospital's humor induction program.

Finally, this study opens up several fruitful avenues for further investigation. Future research should seek to further develop the proposed different functions of humor, which in addition to buffering anxiety also include facilitation of social interaction and group cohesion, as well as denigration of out-groups. It would be of particular interest to map these functions on the tripartite anxiety buffer in Terror Management Theory. Such future work might include an investigation of the effects of individual differences in other types of humor, on classic terror management processes. For example, in addition to trait coping humor, individual differences have been identified in social humor, attitudes towards humor and appreciation of humor (Thorson and Powell, 1993). There is also the potential to investigate the effects of inducing different types of humor on terror management processes, such as Martin et al.'s (2003) self-enhancing, affiliative, aggressive and self-defeating humor. Bespoke, edited and independently-rated video-clips should be used in order to induce different types of humor and provide more highly-matched control groups, which will enable the testing of more complex hypotheses relating to the tripartite terror-management system (Hart et al. 2005) whereby threats to one component of the system (relating to attachment, worldviews or self-esteem) result in compensatory defensive activation of the other components. Ultimately, this avenue of investigation should explore whether humor inductions can be successfully tailored to address the component of an individual's security system that is most seriously threatened, leading to the possibility of one day using bespoke, individualized humor induction interventions in medical settings. 


\section{References}

Alexander, R. D. (1986). Ostracism and indirect reciprocity: The reproductive significance of humor. Ethology and Sociobiology, 7(3-4), 253-270.

Arndt, J., Greenberg, J., Solomon, S., Pyszczynski, T., \& Simon, L. (1997). Suppression, accessibility of death-related thoughts, and cultural worldview defense: exploring the psychodynamics of terror management. Journal of Personality and Social Psychology, 73(1), 5-18.

Bartolo, A., Benuzzi, F., Nocetti, L., Baraldi, P., \& Nichelli, P. (2006). Humor comprehension and appreciation: an FMR.I study. Humor, 18(11), 1789-1798.

Bennett, H. J. (2003). Humor in medicine. Southern Medical Journal Birmingham Alabama, 96(12), 1257-1261.

Berk, R. A. (2015). The greatest veneration: Humor as a coping strategy for the challenges of aging. Social Work in Mental Health, 13(1), 30-47.

British Comedy Guide (2017). Mr. Bean. https://www.comedy.co.uk/tv/ Mr_bean/ (accessed 16 June 2017).

Brône, G., Feyaerts, K., \& Veale, T. (2006). Introduction: Cognitive linguistic approaches to humor. Humor-International Journal of Humor Research, 19 (3), 203-228.

Demjén, Z. (2016). Laughing at cancer: Humor, empowerment, solidarity and coping online. Journal of Pragmatics, 101, 18-30.

Elgee, N. J. (2003). Laughing at death. The Psychoanalytic Review, 90(4: Special issue), 475497.

Fine, G. A., \& Soucey, M. D. (2005). Joking cultures: Humor themes as social regulation in group life. Humor-International Journal of Humor Research, 18(1), 1-22.

Ford, T. E., Ferguson, M. A., Brooks, J. L., \& Hagadone, K. M. (2004). Coping sense of humor reduces effects of stereotype threat on women's math performance. Personality and Social Psychology Bulletin, 30(5), 643-653.

Frankl, V. E. (1984). Man's Search for Meaning: An Introduction to Logotherapy (3rd Ed). New York, NY: Simon \& Schuster.

Frederickson, B. L. (2001).The role of positive emotions in positive psychology. The broaden and build theory of positive emotions. American Psychologist, 56(3) 218-226.

Greenberg, J., Pyszczynski, T. \& Solomon, S. (1986). The causes and consequences of a need for self-esteem: A terror management theory. In R. Baumeister (Ed.) Public Self and Private Self (pp. 189-212). Springer: New York.

Hackney, C. H. (2011). The effect of mortality salience on the evaluation of humorous material. The Journal of Social Psychology, 151(1), 51-62.

Hart, J., Shaver, P. R., \& Goldenberg, J. L. (2005). Attachment, self-esteem, worldviews, and terror management: Evidence for a tripartite security system. Journal of Personality and Social Psychology, 88(6), 999-1013.

Jarvis, A., Worth, A., \& Porter, M. (2006). The experience of caring for someone over 75 years of age: results from a Scottish General Practice population. Journal of Clinical Nursing, 15(11), 1450-1459.

Keltner, Dacher., Lisa Capps, Ann M. Kring, Randall C. Young \& Erin A. Heerey (2001). Just teasing: a conceptual analysis and empirical review. Psychological Bulletin, 127(2), 229.

Kesebir, P. (2014). A quiet ego quiets death anxiety: Humility as an existential anxiety buffer. Journal of Personality and Social Psychology, 106(4), 610-623.

Landau, M. J., Greenberg, J., Solomon, S., Pyszczynski, T., \& Martens, A. (2006). Windows into nothingness: Terror management, meaninglessness, and negative reactions to modern art. Journal of personality and social psychology, 90(6), 879-892. 
Lefcourt, H. M. (2001). Humor: The Psychology of Living Buoyantly. New York: Springer Science \& Business Media.

Lefcourt, H. M., Davidson, K., Shepherd, R., Phillips, M., Prkachin, K., \& Mills, D. (1995). Perspective-taking humor: Accounting for stress moderation. Journal of Social and Clinical Psychology, 14(4), 373-391.

Mager, M., \& Cabe, P. A. (1990). Effect of death anxiety on perception of death-related humor. Psychological Reports, 66(3), 1311-1314.

Martin, R. A., Puhlik-Doris, P., Larsen, G., Gray, J., \& Weir, K. (2003). Individual differences in uses of humor and their relation to psychological well-being: Development of the Humor Styles Questionnaire. Journal of Research in Ppersonality, 37(1), 48-75.

Marziali, E., McDonald, L., \& Donahue, P. (2008). The role of coping humor in the physical and mental health of older adults. Aging and Mental Health, 12(6), 713-718.

Maxwell, W. (2003). The use of gallows humor and dark humor during crisis situations. International Journal of Emergency Mental Health, 5, 93-98.

Merz, E. L., Malcarne, V. L., Hansdottir, I., Furst, D. E., Clements, P. J., \& Weisman, M. H. (2009). A longitudinal analysis of humor coping and quality of life in systemic sclerosis. Psychology, Health \& Medicine, 14(5), 553-566.

Owren, M. J., \& Bachorowski, J. A. (2003). Reconsidering the evolution of nonlinguistic communication: The case of laughter. Journal of Nonverbal Behavior, 27(3), 183200.

Peterson, C., \& Seligman, M. E. (2004). Character Strengths and Virtues: A Handbook and Classification (Vol. 1). Oxford: University Press.

Romundstad, S., Svebak, S., Holen, A., \& Holmen, J. (2016). A 15-year follow-up study of sense of humor and causes of mortality: the Nord-Trøndelag Health Study. Psychosomatic Medicine, 78(3), 345-353.

Rozin, P., Rozin, A., Appel, B., \& Wachtel, C. (2006). Documenting and explaining the common $\mathrm{AAB}$ pattern in music and humor: Establishing and breaking expectations. Emotion, 6(3), 349-355.

Rudnick, A., Kohn, P. M., Edwards, K. R., Podnar, D., Caird, S., \& Martin, R. (2014). Humor-related interventions for people with mental illness: A randomized controlled pilot study. Community Mental Health Journal, 50(6), 737-742.

Shirley, J. (2015). The Importance of Humor for a Healthy Pregnancy. International Journal of Childbirth Education, 30(1), 63-67.

Shiota, M. N., Campos, B., Keltner, D., \& Hertenstein, M. J. (2004). Positive emotion and the regulation of interpersonal relationships. In P. Philippot \& R. S. Feldman (Eds) The Regulation of Emotion (pp. 127-155). New Jersey: Lawrence Erlbaum Associates.

Sliter, M., Kale, A., \& Yuan, Z. (2014). Is humor the best medicine? The buffering effect of coping humor on traumatic stressors in firefighters. Journal of Organizational Behavior, 35(2), 257-272.

Thorson, J. A., \& Powell, F. C. (1993). Development and validation of a multidimensional sense of humor scale. Journal of Clinical Psychology, 49(1), 13-23.

Tremayne, P. (2014). Using humor to enhance the nurse-patient relationship. Nursing Standard, 28(30), 37-40.

Vaillant, G. E. (2000). Adaptive mental mechanisms: Their role in a positive psychology. American Psychologist, 55, 89-98.

Vess, M., Routledge, C., Landau, M. J., \& Arndt, J. (2009). The dynamics of death and meaning: the effects of death-relevant cognitions and personal need for structure on perceptions of meaning in life. Journal of Personality and Social Psychology, 97(4), 728-744. 
Wilkins, J. (2014). The use of cognitive reappraisal and humor as coping strategies for bullied nurses. International Journal of Nursing Practice, 20(3), 283-292. 